\title{
Sales Professionals' Perspective on Digital Marketing in Indian Pharmaceutical Industry
}

\author{
Manoj Kumar ${ }^{1 *}$ and Bhausaheb Londhe ${ }^{2}$ \\ ${ }^{\mathbf{1}}$ Research Scholar, ${ }^{\mathbf{2}}$ Professor, ${ }^{1 \& 2}$ Department of Management Studies \\ Amity University, Mumbai, Maharashtra, India \\ *Corresponding Author \\ E-Mail: manoj.phd2019@gmail.com
}

\begin{abstract}
Indian pharmaceutical industry is one amongst the leading players of pharmaceutical industry around the world. In present digital times, every aspect of the society has been digitalized. There are major transitions noted in pharmaceutical industry as well. Digital technology, has changed the working methods and emerged, as a cost effective means, with impressive target reach around the world. Yet, this platform, is not being utilized to its complete potential, due to the lack of awareness, acceptability and the deficient training of the working personnel. The marketing and sales professionals had a major impact of the digitalization on their working methods. It has changed the traditional marketing methods of industry, resulting in the urgent need of upgradation of the skills of sales professionals. Hence, the views, trainings, awareness and acceptability of sales professionals regarding the digital technology is essential and must be kept into consideration for success of the industry. This is an indispensable component for any pharmaceutical company to attain growth and stand at par with the other pharmaceutical giants around the world. In this study, data of 303 sales professionals was collected and analyzed, recording their perspectives on digital marketing. We found that these professionals were aware and had good acceptability for the same. Most commonly used tools were website promotions, social media advertising, awareness campaigns, creation and management of subject related blogs. These professionals used it extensively on a day-to-day basis, for the maximal benefit of the company with providing the comfort of digitalization to their customers and other users.
\end{abstract}

Keywords: Indian Pharmaceutical Industry, Sales Professionals, Digital Marketing, Sales Team

\section{INTRODUCTION}

Digital marketing in present times, is utmost required to survive in the modern industrial world, with pharmaceutical industry as no exception. Digital marketing is being used in many aspects in the pharmaceutical industry, which is one amongst the highly growing industries around the world. Indian pharmaceutical market, has been reported as one amongst the top five pharmaceutical markets of the world. [1] In the past few years, digital platform has provided a huge growth to this industry, with the creation of mass awareness regarding health and allied sectors. Digital marketing has clearly simplified advertising methods, organization and execution of awareness campaigns, with a benefit of mass reach at lower costs with efficiency. [1,2] Pharmaceutical digital marketing might be executed across the verticals i.e. doctors, hospitals, patients, sales team and health care professionals simultaneously fulfilling different needs at various levels. It also includes the management of digital customer data and electronic customer relationship management (e-CRM) systems. [3] Also, there are many studies reporting, utilization of digital marketing by pharmaceutical companies for its promotions widely. In the recent years, use of digital marketing has permitted companies to adopt a different approach in order to reach the patients, physicians and caregivers. [4] The sales team plays a very important part in the success of any industry. In these digital times, every process is going digital. So, these are the marketing methods of the pharmaceutical industry. Sales professionals have been affected by and large due to this change of marketing techniques from traditional ways to digital ones. These professionals need to be trained and updated in terms of their working skills from time to time. Digital presence on social and professional media sites is essential requirement, for everyone for some or the other reason. This digital presence gives, an added opportunity to the industry to reach their target users by digital promotions and campaigns. Sales professionals are the base pillars of success for these digital promotions and campaigns. It includes sales professionals working from ground-level to the senior most positions.

Hence, this study attempts to gain an understanding and utility of digital marketing tools from the perspective of sales professionals in relation to their work profile and dayto-day applicability. We also analyzed the problems faced by the sales personnel and wanted to develop an understanding by an insight into their field of work, which would be useful for our country to catch up with other pharmaceutical companies from different parts of the world.

\section{MATERIALS AND METHODS}

A total 303 sales professionals from all levels were included in the study. A detailed questionnaire was used to assess the views of sales professionals from pharmaceutical industry on perspective of digital marketing usability problems faced and applicability in their field of work. The questionnaire was developed inclusive of type of digital platform usage, digital tools being used, time allocated to online and offline marketing, with a special emphasis to its utilization and 
applicability for generation of sales and interaction with the end-users by these sales professionals.

\section{RESULTS}

Digital platform is amongst the most widely used platform these days. The details of usage of digital platform by sales professionals have been mentioned in Table I. There was only one participant with rare usage of digital media platform. Majority of the participants were frequent and very frequent users. Mobile was found to be most preferred digital medium by the sales persons followed by e-mail and social networking sites. Connectivity with colleagues and other professionals was the most opted reason for usage of the digital media platform. Other reasons of usage have been listed in Table I.

Table I Preference and Usage Of The Digital Media Platform By Sales Professional

\begin{tabular}{|l|l|c|c|}
\hline \multirow{4}{*}{$\begin{array}{l}\text { How often do you use digital } \\
\text { media? }\end{array}$} & Rarely & Freq. & \% \\
\cline { 2 - 4 } & Occasionally & 1 & 0.33 \\
\cline { 2 - 4 } & Frequently & 14 & 4.62 \\
\cline { 2 - 4 } & Very Frequently & 157 & 51.82 \\
\hline \multirow{4}{*}{$\begin{array}{l}\text { Which digital media do you } \\
\text { prefer the most? }\end{array}$} & E-mail & 131 & 43.23 \\
\cline { 2 - 4 } & Mobile & 187 & 61.72 \\
\cline { 2 - 4 } & Others & 292 & 96.37 \\
\cline { 2 - 4 } & Social network & 10 & 3.3 \\
\cline { 2 - 4 } & Webinar & 170 & 56.11 \\
\hline \multirow{5}{*}{ Why do you use digital media? } & To connect with colleagues and professionals & 246 & 10.23 \\
\cline { 2 - 4 } & To connect with family and friends & 228 & 75.25 \\
\cline { 2 - 4 } & To connect with Healthcare Professionals & 172 & 56.77 \\
\cline { 2 - 4 } & To connect with Patients \& Caregivers & 86 & 28.38 \\
\cline { 2 - 4 } & To stay entertained & 100 & 33 \\
\cline { 2 - 4 } & To stay updated & 195 & 64.36 \\
\hline
\end{tabular}

Type of the digital platforms used by sales professionals have been mentioned in Fig.1. Whatsapp and Facebook were most commonly used social media platform.

\section{Digital platform used by the sales professionals (\%)}

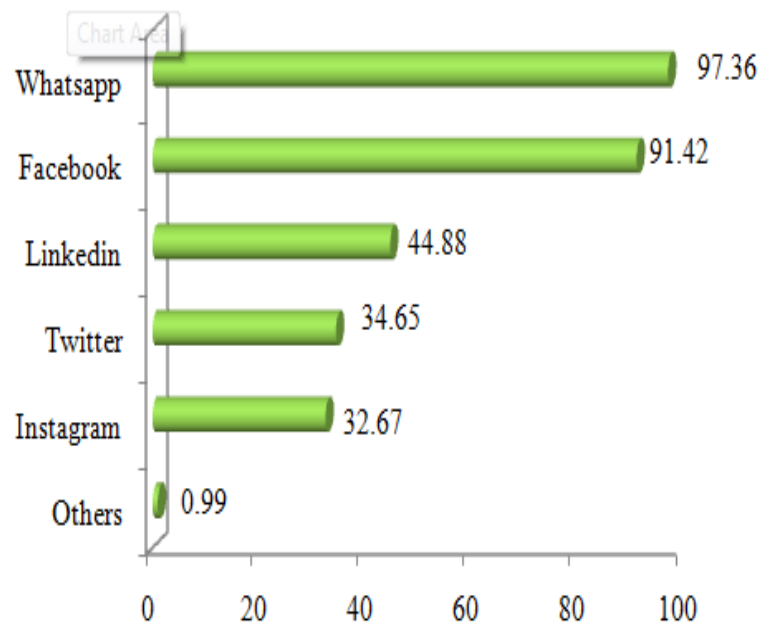

Fig. 1 Digital platform used by sales professionals

The role of digital media or social media in increasing sales was described in Fig.2. Relationship management and better detailing were the top most reasons mentioned by participants of the study closely followed by brand building.
Benefits of digital platform for pharmaceutical companies (\%)

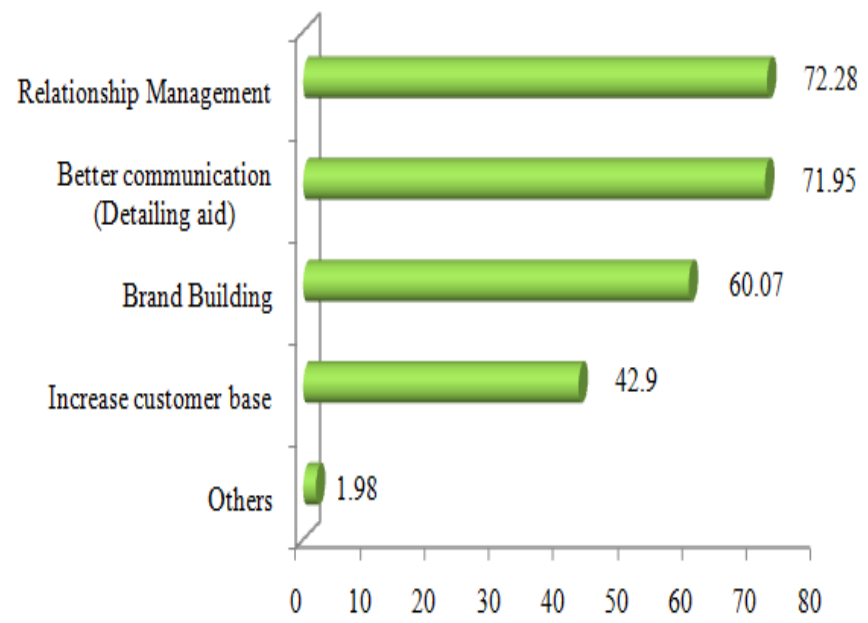

Fig. 2 Benefits of digital platform for pharmaceutical companies

Majority of the sales professional had a weekly visit with customers, and most of them spent 5- 10 minutes with a customer, but the ideal time asked by professionals was 10 20 minutes. Clinical information on the drugs, drug pricing, free drugs provided by the company were the major information shared with the customers on visit. Other details regarding the same have been provided in Table II. 
TABle II Details Of The Customer InTERACtion With SALES Professionals

\begin{tabular}{|c|c|c|c|}
\hline & & Frequency & $\%$ \\
\hline \multirow{5}{*}{$\begin{array}{l}\text { Frequency of visit/interaction with the } \\
\text { customers }\end{array}$} & Never (I would prefer a digital route) & 2 & 0.66 \\
\hline & Once in a week & 201 & 66.34 \\
\hline & Once in two weeks & 70 & 23.1 \\
\hline & Once in a month & 23 & 7.59 \\
\hline & Once in 3-4 months & 7 & 2.31 \\
\hline \multirow{6}{*}{$\begin{array}{l}\text { Time usually spent with each } \\
\text { customer }\end{array}$} & Not at a defined frequency, only on need basis & 34 & 11.22 \\
\hline & Less than 2 minutes & 6 & 1.98 \\
\hline & 2-5 minutes & 62 & 20.46 \\
\hline & 5-10 minutes & 137 & 45.21 \\
\hline & 10-20 minutes & 47 & 15.51 \\
\hline & 20-30 minutes & 17 & 5.61 \\
\hline \multirow{6}{*}{$\begin{array}{l}\text { Ideal time sales persons willing to } \\
\text { spend with customers }\end{array}$} & Not at a defined frequency, only on need basis & 39 & 12.87 \\
\hline & Less than 2 minutes & 1 & 0.33 \\
\hline & 2-5 minutes & 20 & 6.6 \\
\hline & 5-10 minutes & 83 & 27.39 \\
\hline & 10-20 minutes & 119 & 39.27 \\
\hline & 20-30 minutes & 41 & 13.53 \\
\hline \multirow{6}{*}{$\begin{array}{l}\text { Information/Value addition provided } \\
\text { customers }\end{array}$} & $\begin{array}{l}\text { Clinical information on the drugs such as latest trials } \\
\text { etc. }\end{array}$ & 265 & 87.46 \\
\hline & $\begin{array}{l}\text { Information on pricing, company support on free } \\
\text { drugs, availability etc. }\end{array}$ & 259 & 85.48 \\
\hline & $\begin{array}{l}\text { Information / leaflet, brochure on drugs, dosing for } \\
\text { the patients }\end{array}$ & 231 & 76.24 \\
\hline & Do's \& don'ts for patients & 94 & 31.02 \\
\hline & $\begin{array}{l}\text { Diets, nutrition \& exercise information for the } \\
\text { patients }\end{array}$ & 48 & 15.84 \\
\hline & Others & 11 & 3.63 \\
\hline
\end{tabular}

Engagement of the sales personnel in digital marketing services (\%)

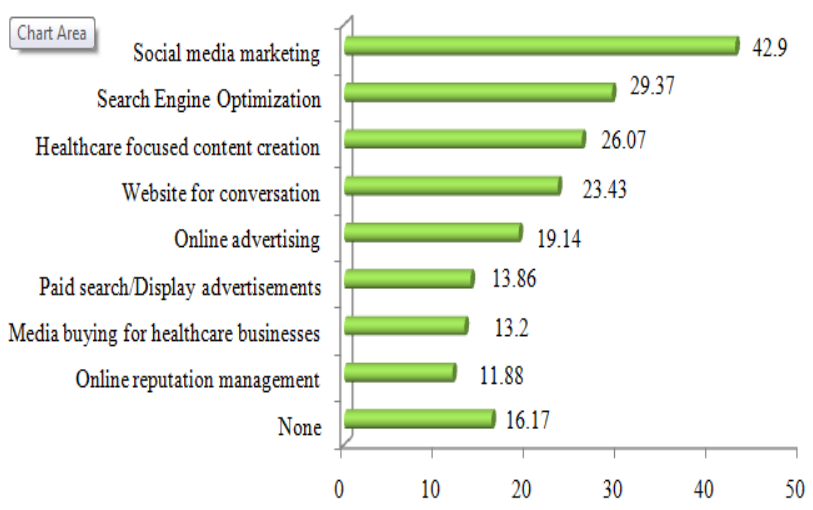

Fig. 3 Engagement of the sales personnel in digital marketing services

Fig. 3 explained the level of engagement of sales professionals in different digital marketing tools. Social media marketing was the most utilised tool of digital platform with $42.9 \%$ of sales professionals working on it. Most of higher level professionals had to use social media for marketing along with the traditional marketing methods for the synergystic effect to increase sales. Other involvements of the participants of the study at the digital platform have been mentioned in the Fig. 3 .

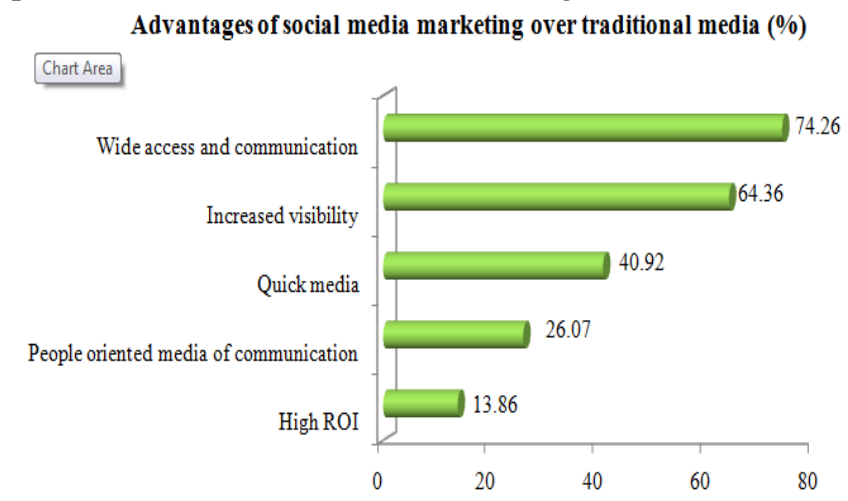

Fig. 4 Advantages of digital media marketing over traditional media

Advantages of digital platform over the traditional methods of marketing have been shown in Fig. 4. Wide access and communication was major advantage of digital platform marketing as mentioned by 74.26 participants over the traditional methods. The second advantage of marketing via digital medium was remarked as increased visibility by $64.36 \%$ of the sales professionals. 
Role and uses of digital platform as per the views of the study participants have been mentioned elaborately in table III. Majority of the sales professionals agreed in unison to the usability of this platform in work with most of them using social media platform for varied professional activities. Most of the professionals mentioned that there was 30-60 minutes of online presence of customers per day. Frequently most of the customers spent almost an hour every day on these social networking sites, which helped majority $(\sim 70 \%)$ of sales persons to reach their customers, share information and maintain thier relationship with ease. Apart from the benefits of social media, there were some disadvantages of reported by the sales professionals. The most agreed was, the lack of privacy followed by misuse of $24 \times 7$ availibility on the digital platform.

Table III Role And Use Of Digital Platform In Form Of Social Media: Views Of Sales Professionals

\begin{tabular}{|c|c|c|c|}
\hline & & Frequency & $\%$ \\
\hline \multirow{2}{*}{ Role of digital platform usage in work place } & No & 9 & 2.97 \\
\hline & Yes & 294 & 97.03 \\
\hline \multirow{2}{*}{ Use of any form of Social Media } & No & 6 & 1.98 \\
\hline & Yes & 297 & 98.02 \\
\hline \multirow{5}{*}{$\begin{array}{l}\text { Frequency of iPad usage and other similar } \\
\text { based interactions }\end{array}$} & $\begin{array}{l}<25 \% \text { - Rarely, as customers prefer human } \\
\text { interaction }\end{array}$ & 24 & 7.92 \\
\hline & $\begin{array}{l}>25 \% \text {-When information is unique and requires } \\
\text { iPad based discussions }\end{array}$ & 92 & 30.36 \\
\hline & $>50 \%$ - Quite Frequently & 106 & 34.98 \\
\hline & $>80-100 \%-$ Almost in every call & 75 & 24.75 \\
\hline & Others & 6 & 1.98 \\
\hline \multirow{5}{*}{$\begin{array}{l}\text { Customers usage of digital platform to } \\
\text { disseminate knowledge, interact with \& } \\
\text { schedule appointments etc. }\end{array}$} & Frequently & 146 & 48.18 \\
\hline & Occasionally & 94 & 31.02 \\
\hline & Rarely & 24 & 7.92 \\
\hline & Very Frequently & 29 & 9.57 \\
\hline & Very Rarely & 10 & 3.3 \\
\hline \multirow{5}{*}{$\begin{array}{l}\text { Average time spent on social networking sites } \\
\text { per day }\end{array}$} & 15 mins or less & 21 & 6.93 \\
\hline & $15-30 \mathrm{mins}$ & 96 & 31.68 \\
\hline & $30-60$ mins & 127 & 41.91 \\
\hline & 60-120 Minutes & 40 & 13.2 \\
\hline & more than 120 mins & 19 & 6.27 \\
\hline \multirow{5}{*}{ Reasons to prefer use of social media in work } & Increase customer base & 89 & 29.37 \\
\hline & Relationship Management & 214 & 70.63 \\
\hline & Share Information with customers & 218 & 71.95 \\
\hline & Take Appointments & 98 & 32.34 \\
\hline & To stay updated & 256 & 84.49 \\
\hline \multirow{5}{*}{$\begin{array}{l}\% \text { of your customer base are a part of your } \\
\text { social media list/ group }\end{array}$} & $0-20 \%$ & 24 & 7.92 \\
\hline & $20-40 \%$ & 59 & 19.47 \\
\hline & $40-60 \%$ & 84 & 27.72 \\
\hline & $60-80 \%$ & 89 & 29.37 \\
\hline & $80-100 \%$ & 44 & 14.52 \\
\hline \multirow{5}{*}{ Downsides of social media } & No customers are part of my social media & 3 & 0.99 \\
\hline & Authenticity and privacy problems & 213 & 70.3 \\
\hline & Constant updating is required & 80 & 26.4 \\
\hline & Misuse of the media for communication & 179 & 59.08 \\
\hline & Problem of reach and connectivity & 54 & 17.82 \\
\hline
\end{tabular}

\section{DISCUSSION}

In present digital times, it is important for every business to mark its digital presence, with pharmaceutical industry as no exception. Pharmaceutical industries have changed its marketing methods drastically to survive in this digitalized world. [2] There are many tools which are being used widely to increase reach to the target population. Some of them are having company's websites, mobile applications, blogs and forums. [3,4] Apart these, companies are using both the social and professional networking sites to gain extension to newer territories. Sales professionals are most 
important to achieve these targets and need to be trained extensively as per the current emerging demands of the industry. So, pharmaceutical companies keep a regular check and train these professionals as per the market demands. Sales professionals, on the other hand, are actively participating and inculcating digital skills. There are making a visible impression by social and professional media platforms. The most popular amongst all these connectivity platforms are whatsapp and facebook. These are most used due to the availibility of customers on these sites, in huge numbers. These social media platforms provide direct connectivity and help develop a better relationship with the customers with a one on one access, which is another main reason for chosing these social media platforms. [5] Social media undoubtedly offers clear connectivity resulting in linear propotionality with the amount of sales. Sales team can acquire a large amount of information about their costumers with the help of social media and can design their marketing and sales strategies as per the needs of the customers. Research reports have mentioned that many of the sales professionals are continuously polishing their skills and have increased the use of the digital marketing methods along with the traditional methods. [6] As per the views of the sales professionals digital connectivity not only offers better connectiovity but also helps in brand creation and increase the customer base. The same has been reported in other such studies too. [7] Also, digital and social media marketing have been proclaimed by most of the participants in our study to have positive effects on the company's growth. [6,8] Researchers from different parts of the world have recorded the same. $[9,10,11]$ The digital platform have been under utilized in terms of sales professionals. A report mentioned that Indian pharma companies would have to develop a digital culture and allocate different resources for the same. [12] Social media marketing was used the most by the companies, with majority of the professionals assigned to the same. The mode of advertising, have changed drastically from print media to social media in this digital world. Thus, social media mareketing has taken over and transformed the traditional marketing methods in to the current digital ones. $[13,14]$ Apart all the mentioned benefits of the digital platform as mentioned by the sales professionals there were a few disadvantages noted too. The top most of them was the lack of privacy. Due to the availibility on the digital platform, there has been a siginificant lack of privacy as one could be contacted any time any place, as availability on one or the other site is there. This communication methods or availability on social or professional media, was also largely reported being misused by the sales professionals, as many of the sales professionals were connected to their customers ranging from a few to all of them on one or more digital platform. Digital connectivity where simplified the business and working methods on one side, has disturbed the work-life balance on the other hand.

\section{CONCLUSION}

In Indian marketing industry, digitalization has made its way amidst the traditional approach. Marketing methods have gone digital, with sales professionals being confronted the most on various digital platforms. Sales professionals are a very important part of the industry. In this digitalised world, it is mandatory to update the skills of the sales professionals to compete with the modern peers from all aorund the world. Hence, the sales professionals notion and understanding for the digital platform is exigent and can not be over looked by the management.

\section{REFERENCES}

[1] Reddy, A. V. J., \& Rao, B. M. (2017). Opportunities and challenges for Indian Pharmaceutical companies in overseas markets and need of digital tools for sustainable success. Indian Journal of Pharmaceutical Education and Research, 51, 226-238.

[2] Kumar, M., \& Londhe, B. (2019). Relevance and impact of digital marketing in Indian pharmaceutical industry with specific reference to super specialists doctors. International Journal of Interdisciplinary Research and Innovations, 7(2). 1-7.

[3] Bhole, L., \& Verma, S. (2018). Digital Marketing: A Road Ahead To Pharmaceutical Selling. IOSR Journal of Business and Management, 61-65.

[4] Champagne, D., Hung, A., \& Leclerc, O. (2015). The Road to Digital Success in Pharma. Retrieved from: https://www.mckinsey.com /industries/pharmaceuticals-and-medical-products/our-insights/theroad-to-digital-success-in-pharma (Accessed 29 Mar. 2018).

[5] Agrawal, S., \& Kaur, N. (2015). Influence of Social Media Marketing in Indian Pharmaceutical Industry. International Journal of Advance Research and Innovation, 3(4). 735-738.

[6] Tambe, S., Bhat, K., More, M. \& Nair, P. (2014). Perceptions of the use of social media in the Indian pharmaceutical industry: A survey of marketing, advertising and medical professionals. SIES Journal of Pharma-Bio Management, 2(1). 72-84.

[7] Mahajan, V., Nauriyal, D. K., \& Singh, S. P. (2018). Domestic market competitiveness of Indian drug and pharmaceutical industry. Review of Managerial Science, 1-41.

[8] Das, B., \& Subudhi, R. (2016). Engagement pattern of customers in digital \& social media marketing: A study on effect of age group. Parikalpana: KIIT Journal of Management, 12(1).

[9] Agnihotri, R., Kothandaraman, P., Kashyap, R., \& Singh, R. (2012). Bringing "social" into sales: The impact of salespeople's social media use on service behaviors and value creation. Journal of Personal Selling \& Sales Management, 32(3), 333-348.

[10] Clark, M., \& Melancon, J. (2013). The influence of social media investment on relational outcomes: A relationship marketing perspective. International Journal of Marketing Studies, 5(4), 132.

[11] Plangger, K. (2012). The power of popularity: how the size of a virtual community adds to firm value. Journal of Public affairs, 12(2), 145-153.

[12] Reinventing pharma sales and marketing through digital in India: Current assessment, gap analysis and future reality. Retrieved from: https://www.ey.com/Publication/vwLUAssets/ey-reinventing pharma 1\%24FILE/ey-reinventing- pharma.pdf. (Accessed on 15 April 2019).

[13] Gupta, P., \& Udupa, A. (2011). Social media marketing by pharmaceutical industry: perception and attitudes of key stakeholders. Business and Economics Journal.

[14] Jhajharia R. (2017). Digital Marketing in Pharma Industry: A Complete Guide: Digital Marketing \& Data Analytics Blog. Digital Vidya. Retrieved from: https://www.digitalvidya.com/blog/digitalmarketing-in-pharma-industry/ (Accessed on 30 April 2019) 2017. 